Available online at: http://tsdr.psdku.unpad.ac.id

Tourism and Sustainable Development Review Journal (TSDR)

Volume 1 Number 1 (2020): 6-13

\title{
Children - Centered Business Models in Tourism
}

\author{
Alina Beisembayeva, Daniel Marco-Stefan Kleber \\ Academic Department of Business Administration, MODUL University Dubai, UAE
}

\begin{abstract}
Since 2016, a number of research activities on topics such as children's tourism in Kazakhstan, family tourism in Dubai, and children's tourism in Dubai were conducted by the authors. During previous research and based on personal experience in Almaty and Dubai, the authors realized that in these cities, and most probably in these countries, the business model of children camps is different. In addition, the authors identified a diverse understanding of children's tourism. The aim of this research is to explain children's tourism, to identify children's tourism products, and the business models value. This research is done by analyzing secondary data collected from diverse sources in Russian and English languages, which are giving the possibility to analyze the situation from different perspectives and to compare children-centered business models in tourism. One of the most widespread types of tourism is youth tourism, including schoolchildren, aged 7 to 17 years, who travel under supervision with different goals and objectives. Russian scientists believe that in the future, youth tourism has the potential to become one of the priority directions of tourism development. The economic advantages of this type of tourism can be identified as follows: schoolchildren and students travel usually happens in organized groups, rhythmically repetitive trips from year to year, which facilitates business planning. The limitations of this research are that children's tourism is not well explained in English scientific literature, as children's tourism is usually understood as a part of family tourism in the English speaking society. The study of children in tourism is a relatively new endeavor in tourism studies. Usually, tourism research on children mainly focuses on children's exploitation or on other negative effects of tourism on the social environment.
\end{abstract}

Keywords: Children's Tourism; Children's Tourism Products; Children Camps; Value Creation; Business Models; Sustainable Value of Children's Tourism

\section{This is an open access article under the CC-BY-NC license.}

\section{INTRODUCTION}

Identification of the Problem

Children centered studies is a relatively new research field in tourism. Children's tourism as a special and individual type of tourism is unknown in English tourism literature. Children tourism usually studied in researches about child protection because of the negative social impact of tourism: child exploitation, sex tourism with children, etc. Children's as travelers are usually solely mentioned as a part of family tourism. The same problem was mentioned by a number of scientists in their research on topics such as "progressing a child-centered research agenda in tourism studies" (Graham A., 2019). Comparing Russian and English literature, Russian authors of tourism books and articles tend to describe children's tourism as an independent type of tourism (Lojko 0., 2005).

Corresponding author

AlinaBeisembayeva@gmail.com

DOI: https://doi.org/10.31098/tsdr.v1i1.3 


\section{Aims of the research}

The motivation behind this project is based on the fact that children's tourism is a rather underdeveloped niche. There is no consensus about a clearly defined explanation regarding children's tourism business models and how various forms of them may bring benefits to the social, environmental, and economic development.

The purpose of the study and aim of this research is to:

- Explain and describe the term children's tourism by analyzing the available literature

- Explain which type of products/services are related to children-centered business models

- Analyze the children's camps business model as a business model for value creation

\section{LITERATURE REVIEW}

Tourism as a social phenomenon was the brainchild of the industrial revolution, which caused the collapse of feudalism in Western Europe and gave rise to new demands on the education of the younger generation in the late XVII - early XVIII century. In educational institutions in England, France, Germany, Austria, and other countries, when studying certain subjects, teachers began to use walks and trips to the neighborhood city as part of work with students. These simplest forms of travel were defined as excursions. The great Slavic teacher Ya. A. Komensky (1592-1670) demanded the inclusion of outdoor games and traveled in the system of education and upbringing of children and adolescents (Ostapets, 2001).

The pedagogical value of the journey, as indicated by the Russian revolutionary democrat N.G. Chernyshevsky, to believe that no schoolwork and no work on the candidate's, master's or doctoral theses don't benefit to the young as traveling. (Chernyshevsky, 1953).

In 2017 Gomilevskaya Galina Aleksandrovna, candidate of economic sciences, director of International Institute of tourism and hospitality in the article of "Development Children's tourism as an industrial segment of social economy: world experience and regional features," mentioned that the specifics of the formation and development of children's tourism is directly related to the forms of social interactions between enterprises of the tourism industry, government agencies, public organizations and directly by consumers of children's tourism and their official representatives. Children's tourism is considered through the system of socio-economic relations in the development of human capital, methods of state regulation, and mechanisms of publicprivate partnership (Gomilevskaya, 2017).

Children and youth tourism are one of the most effective health technologies. One of the important goals of youth tourism, rehabilitation and activity is the formation of a healthy lifestyle of a person and society as a whole, which is of great public importance in the upbringing of children (Lojko, 2005).

Explanation of children - centered business models in tourism

Children's tourism is a type of tourism, which is consumed by children aged from 7 to 17 years old, who travel on duration from 24 hours to 6 months continuously, for at least one overnight 
stay aiming at relaxation, recovery, education, communication and other aims accompanied by a supervisor (responsible adult) or instructor of this tourist group (Golikova, 2013).

The demand for children's tourism, as well as the offer, is most pronounced seasonal in nature and depends on school holidays. The summer period is considered the "highest" season since it is during this period that both the demand and the supply are equally high and stable. Children's tourism is a children's activity, designed for a child's leisure time away from adults. The most popular children's holiday centers in the world are children's camps. In these camps, the child does not only rests but also communicates with other children, learns new skills, further improves existing ones and travels. Competent teachers and specialists work in the children's camps as they bear constant responsibility for the child (Morozov, 2004).

Children's camps are increasingly popular around the world. However, they are not mentioned as children's tourism. Konstantinos and Kouthouris (2005), in their research on the topic "Personal incentives for participation in summer children's camps: investigating their relationships with satisfaction and loyalty," mentioned that in the last 20 years, the children summer camp industry has become very competitive in Greece. Camp managers are tried to adopt a customer-driven approach in order to build campers' loyalty (Konstantinos and Kouthouris, 2005).

Research indicates that in some parts of the world, children's tourism has already been popular several years ago and was an actual topic for marketing research to improve this highly demanding business.

Historical background of children's camps.

In 1876, the first children's camp for recreation and development of the younger generation was founded in Switzerland. Pastor Hermann Walter Bion became the organizer of the holiday camp, who brought the children to the Alps, helped them build tents at home, fly kites, teach and sing songs. The pastor served in Zurich and often took the children with him to nearby villages. During the first camp, which was organized by him, there were 68 children, and volunteering parents helped to look after them. The first camps and its conditions were very close to the Spartan: girls were settled by local families, and the boys spent the night in haystacks. In addition to entertainment, children did household chores and helped to collect fruits and flowers in their leisure time. After the first experimental rest, the pastor noted that the children returned home healthier as the fresh air and physical activity favorably affected the general condition of the children. Since that time, it was decided to organize holiday camps for children on an annual basis. And shortly after that, representatives in France started to experiment with children camps as well.

In the 1880s, children's camps appeared in North America, but here they were private and functioned for children from elitist families only. For ten years, American camps have gained immense popularity, and their corps were built in the deep forests of New England, where children were protected from the temptations of big cities. In 1885, the first camp was organized with standards that were similar to a military level. Fifteen years later, an approximate number of 5,000 boys participated in the leisure activity, and another 15 years later - almost five times more. In such camps, the luxury did not exist: children spent the night in tents and in sleeping bags. The improvised parade-ground was used for training in gymnastics and morning constructions. Over time, girls did also get the opportunity to attend such places (Riocamp, 2018). 
In addition, the "American Boy Scout" movement has to be mentioned. It was founded in 1908 in England by Colonel Baden Powell, who organized the first scout camp on Lake Brownsea and wrote the book "Scouting for Boys". The colonel was convinced that the young English men needed more severe hardening, physical training, and independence skills. The American Boy Scout Organization (BSA) was established in Chicago on February 8, 1910, by William Boyce. In the mid1930s, there were about three hundred scout camps in the United States. Boys and girls were trained in gymnastics, swimming, methods of survival in the wild, and decorative and applied arts. In the evenings, all the children gathered around the fire: songs were heard, stories sounded, performances were shown (History.com Editors, 2009).

Moreover, the Russian starting point of the history of the children's camps can be considered the year 1925, with the foundation of Artek camps. The fact that children should be in the camp during summer periods in order to rest and to improve their health was firstly mentioned by Zinovy Soloviev. Artek became the first camp-sanatorium. When other camps began to appear, their main focus was on military-patriotic and sports education. In order to become a counselor supervisor, it was necessary to pass through a thorough selection process. In those years, the pioneer movement rapidly developed in the USSR. As a consequence of that, the pioneer camps grew. Then the scout camps became the main reference point, but USSR children did not physically cope with the Spartan conditions after the war and famine. Zinovy Solovyov and his colleagues believed that it was necessary to develop not only children's clinics but also comprehensive health and educational institutions for children, which would take into account their state of health and age. Many physicians confronted Solovyov, arguing that children need a benign regime. To solve this problem, Artek was founded (Riocamp, 2018).

In Soviet times, pioneer camps, which were originally created for adolescents 11-13 years old, allowed most of the country's children to rest outside their homes during school holidays and provided educational, recreational, and ideological work. According to the "Regulations on the country pioneer camp" from 1978, the pioneer camp was considered as an out-of-school recreational institution, organized for pioneers and schoolchildren by councils and trade union committees together with enterprises, institutions and organizations during the winter and summer holidays. In the Soviet Union, up to 1,100 pioneer camps and 540 out-of-town kindergartens and day nurseries were organized. In connection with the reorganization of the pioneer organization in the late 1980s, most of the camps ceased to exist as their financial structure turned out to be unsustainable and less consistent. Nevertheless, some enterprises have found ways to financially secure their camps and determine the pedagogical line of work. Former pioneer camps rebranded themselves as children's recreation camps, centers, complexes, etc. (Travel agency "Golden Fish", 2009).

\section{Classification of children's camp}

Children's camps are supervised programs for children and/or teenagers conducted during the summer months in some countries. Children and teenagers who attend summer camp are known as tourists. This is the most common way of organizing children's activities during the summer holidays, in Russia as well as in the Western world.

In order to determine the characteristics of the organization of children's camp activities, it is necessary to understand which types of children's camps exist. 
Currently, there are different classifications of children's camps:

Classification by activity time:

- Year-round - work throughout the year;

- Seasonal - work during the summer (summer camp), autumn, winter (ski resorts) and spring break;

- Weekend camp

Classification by the venue:

- Stationary - located in the same place, in capital buildings-buildings;

- Tent - can be located in any place where you can set up several large tents;

- Outbound - camps that each time rent premises for a shift (base of other camps, hotels, lodgings, or recreation centers) in different places.

Classification by the length of stay:

- Longtime camps usually 7-21 days camps with overnight stays. Children are living on the camp territory or traveling with the camping, but not going home during the season. Children are fully supervised by a counselor supervisor.

- Day camps are located on the basis of schools and institutions of additional education. Parallels to traditional kindergartens can be established. It functions only in the daytime (as an option - from the morning and only until lunch). During the day, children are engaged in various clubs, sections, walk on the school playground, go on excursions.

According to the content of the program longtime stay camps could concentrate on: sports; linguistic; general health; medical correction, sanatorium; cultural and educational; psychological training, for example, leadership training for adolescents; camps with training program; environmental camps; camps for girls, a school of good manners; labor camps; art camps: theater, music, dance and others (Bondar, 2008).

\section{RESEARCH METHOD}

The research at hand consists of primary and secondary data analysis. Firstly, a critical content analysis of secondary data was conducted. Primary qualitative and quantitative data was collected for this research by mixed-method, as well as author ${ }^{1}$ can refer to her personal experiences in the field of children's tourism.

Aiming at an analysis of the situation from a different perspective, the overall methodological approach for investing the research problem, the authors applied a mixed-methods approach, which includes both: quantitative and qualitative data. The methodology used by the study has been chosen in order to obtain information and draw conclusions about the children's tourism aspect.

The qualitative method helps to collect new data from the potential customers and suppliers of children's tourism. For that purpose, interviews, which include open-ended questions, were used. The goal of qualitative research is to collect in-depth information from people who are directly related to the topic of the research. Qualitative research helps to better understand the nature of children's tourism problems and helps to internally review the current situation. The use of the comparison means that one piece of data is compared with previous data and not consider 
on its own, which gives opportunity researchers to treat data as a whole, rather than to fragment it. Constant comparison enables researchers to identify the strength and weaknesses of children's tourism and emerging problems within that project, drawing on the experience of suppliers. The questions were concentrated on collecting information about children's organizations and how the camps connect with their previous customers. Future expectations and strategic plans within the camp were considered, as well.

In order to collect primary data, the questionnaire survey technique was used. For the purpose of this study, random probability sampling was selected. Social research methods explain the probability sampling as the method of sampling that utilized a form of random selection.

In-depth interview surveys included three groups:

- Suppliers (representatives of Businesses whose products/services are in Children's tourism field)

- Buyers (parents, who are not direct users of the products/services, but paying for that

- Users (children, who are the users of children's tourism products/services)

This sample is based on the need to gain additional information to analyze the topic from a different point of view.

\section{FINDINGS AND DISCUSSION}

In the modern world, the value of additional education as the most important factor in the formation of a new quality of the economy and society increases with the growth of the influence of human capital. Education is defined as a process and result of learning systematized knowledge and skills, it is complemented by a target to reflect the general scientific picture of the modern world presented in global studies, and is also interpreted as a mechanism for the transfer of knowledge continuously developed by science and culture.

First of all, it is necessary to pay attention to preparing the generation $\mathrm{z}$ for future work under the fast-changing and new economic conditions. This means that a radical modernization of the system of additional tourist and local history education of children is needed, with a reorientation towards the upbringing of a socially responsible, independent, and creative person.

Currently, living in an environmentally unfriendly surrounding caused by the action of substances which are harmful to the body (industrial and automobile gases, toxic chemicals, fertilizers, food additives) became usual. That is why now the problem "Environment and human health" becomes acute. The environmental aspect of children's tourism includes the formation of a conscious and sustainable attitude towards the natural environment in order to protect and to make rational use of natural resources.

In modern sociocultural conditions, human values, which are based on a cultural-national basis, receive priority importance. It is obvious that the process of socialization of the personality of a young person needs pedagogical instrumentation, which allows eliminating or at least smooth out the negative impact of the unorganized social environment on the emerging personality. In this regard, one of the most important tasks when educating children and young people in the development of national identity, the formation of a value-based attitude to the mentality, culture, traditions of different nations, which can be achieved through the organization of additional tourist and local history education of students in educational institutions of various types. 
It should be noted that educational activities in association with tourist and local authorities can be based on the following ideas:

- Accessibility (the ability of anyone who wants to join the world of health, sport, beauty, friendship, to choose a feasible route for themselves, a feasible form of participation);

- Consistency (step by step, from simple to complex, each year of study expands and deepens the knowledge and skills);

- Collectivity (the formation of the "responsible dependence" of each child on the collective as a whole);

- Creative activity (each child is given the opportunity to express themselves in different roles - from the performer to the organizer of tourist affairs).

\section{CONCLUSION}

The children-centered business models have a huge value in a modern dynamic environment as they have the potential of causing impact for future generations. In addition, tourism has a sociocultural potential and is an important ecological, moral, aesthetic, and educational element that may bring added value to the young generation. Consequently, the importance of childrencentered tourism can be identified. Nowadays, it is mandatory to give children the right support and understanding of shared values and beliefs. Children-centered business models could, therefore, become models of value creation toward sustainable development. It is essential that entrepreneurs that are working with children-centered business model realize the responsibility of their business.

\section{REFERENCES}

Beisembayeva, A. (2017). Children's tourism in Kazakhstan.

Bibliofond. (2014). Children's Tourism. Accessed on 11 10, 2018, from Bibliofond: https://www.bibliofond.ru/view.aspx?id=730978.

Bondar, V. (2008). Organization of summer holidays for children, taking into account the state of their health on the basis of urban educational institutions. Moskov: Methodical recommendations.

Business Poisk. (2018). Organization of children's tourism. Retrieved from business-poisk.com: http://business-poisk.com/organizatsiya-detskogo-turizma.html.

Chernyshevsky, N. (1953). Selected pedagogical works. Moskov.

Edarabia. (2017). 25 Best Summer Camps in Dubai. Retrieved from Edarabia: https://www.edarabia.com/11-best-summer-camps-in-dubai/.

Golikova, O. (2013). Research Of The Main Directions Of Children's Tourism. FGBOU VPO "Russian State University of Tourism and Service", Moscow.

Gomilevskaya, G. (2017). Development Of Children's Tourism As Industrial Segment Of Social Economy: World Experience And Regional Features (On Axample Of Primorye Territory).

Canosa, A., Graham, A., Wilson, E., (2019). Progressing a child - centered research agenda in tourism studies. Tourism Analysis, Vol. 24, pp. 95-100

History.com Editors. (2009). Boy Scouts movement begins. Accessed on November 24, 2018, from History: https://www.history.com/this-day-in-history/boy-scouts-movement-begins.

Kouthouris, C. Personal incentives for participation in summer children's camps: Investigating their relationships with satisfaction and loyalty. Managing Leisure, 2005, 10(1): 39-53.

Lojko. O. (2005). Tourism and hospitality. Accessed on 2018, from Tourism Library: http://tourlib.net/books_tourism/lojko4-9.htm. 
Morozov, M. (2004). Marketing research of the Russian market of children's tourism. Journal of Marketing in Russia and Abroad.

Ostapets, A. (2001). Pedagogy and psychology of tourist and local history activities of students. Moskow: PMAT. Retrieved from http://tourlib.net/books_tourism/ostapec1.htm.

Pantikapei. (2016). History of children's holiday camps. Retrieved from Pantikapei.ru: http://pantikapei.ru/istoriya-detskix-lagerej-otdyxa.html.

Riocamp. (2018). The story of the emergence of children's camps. Retrieved from Rio Camp: https://riocamp.ru/info/interesnyye-fakty/istorija-pojavlenija-detskih-lagerej.html.

Sincero, S. (t.thn.). Personal Interview Survey. Retrieved from Explorable: https://explorable.com/personal-interview-survey.

Tech Target. (t.thn.). Sample definition. Retrieved from Tech Target: https://whatis.techtarget.com/definition/sample.

Travel agency "Golden Fish". (2009). The history of the development of children's camps and children's activities. Life Journal. 